Han N. Lim • Gary D. Berkovitz • Ieuan A. Hughes • J. Ross Hawkins

\title{
Mutation analysis of subjects with $46, X X$ sex reversal and $46, X Y$ gonadal dysgenesis does not support the involvement of SOX3 in testis determination
}

Published online: 9 July 2004

(C) Springer-Verlag 2004

\section{Hum Genet (2000) 107:650-652}

The numbering of the SOX3 nucleotide variants should read $1050 \mathrm{C} / \mathrm{T}$ and $1173 \mathrm{~A} / \mathrm{C}$ (nucleotide numbering according to GenBank accession number X71135). We stress that the codon numbering is correct and that the nucleotide variants are silent changes in the third base position of tyrosine (codon 203) and alanine (codon 244) respectively. The results and conclusions of the study are unaffected. We regret any inconvenience this error may have caused.

The online version of the original article can be found at http://dx. doi.org/10.1007/s004390000428

H. N. Lim $(\bowtie) \cdot$ G. D. Berkovitz · I. A. Hughes · J. R. Hawkins Department of Paediatrics, University of Cambridge, Box 116, Level 8, Addenbrooke's Hospital, Cambridge CB2 2QQ, UK,

e-mail: hanlim@mit.edu

Tel.: +1-617-4523894

Fax: +1-617-2586883

G. D. Berkovitz

University of Miami School of Medicine, Mailman Center for Child Development 3044A, 1601 NW 12th Avenue, Miami, FL 33136, USA

Present address:

H. N. Lim

Department of Physics, 13-2042, Massachusetts Institute of Technology, 77 Massachusetts Avenue, Cambridge, MA 02139, USA

Present address:

J. R. Hawkins

Cell Biology and Imaging, national Institute for Biological Standards and Control, Blanche Lane, Potters Bar, Herts, ENG 3QG, UK 